\title{
ASSESSMENT OF THE ENDOVASCULAR MANAGEMENT OF FLUSH SUPERFICIAL FEMORAL ARTERY (SFA) TOTAL OCCLUSION
}

\author{
By
}

\section{Mohamed Abd El-Hamied Abd El-Rhman, Mohamed Yahia Zakaria, and Karim Mohamady Eid Mohamady*}

Vascular Surgery Department, Al -Azhar University, Cairo, Egypt

Corresponding author: Karim Mohamady Eid Mohamady, E-Mail: karimalmohamady@gmail.com

\begin{abstract}
Background: Involvement of the superficial femoral artery (SFA) in occlusive peripheral arterial disease (PAD) is extremely common representing $80 \%$ of the symptomatic patients undergoing angiography.

Objectives: This study aimed to assess the endovascular management of flush SFA total occlusion in patients with PAD and with critical chronic lower limb ischemia due to flush occlusion of the SFA in the Vascular Surgery Department in Al-Azhar University Hospitals.

Patients and Methods: Patients with chronic PAD and aged 40-65 years, with SFA flush total occlusion including heavily calcified, long, and fibrotic lesions, and the occlusions up to $15 \mathrm{~cm}$ long in the SFA were included in the current study. Patients were subjected either to contralateral approach, ipsilateral antegrade approach, ipsilateral horizontal puncture, or retrograde access to the SFA via popliteal or dorsalis pedis.

Results: An overall 20 patients were enrolled in the current study with a mean age of $59.5 \pm 6.77$ years. There were $55 \%$ females and $45 \%$ males. The risk factors distribution among the studied group were diabetes mellitus (100\%), hypertension (65\%), smoking (65\%), chronic hepatic disease $(65 \%)$, dyslipidemia $(55 \%)$, and only $5 \%$ had chronic vascular disease. Patients were clinically presented by toe gangrene $(35 \%)$, followed by foot gangrene (25\%), as the main presentation.

Conclusion: Endovascular management strategies of flush SFA total occlusion in patients with PAD due to SFA total occlusion can be safely used with acceptable technical success, short term patency rates, and limb salvage.
\end{abstract}

Keywords: Angioplasty-Stents -Endovascular.

\section{INTRODUCTION}

Approximately, 8.5 million adults are affected by peripheral arterial disease (PAD). Endovascular interventions can be performed to treat chronic limb ischemia (CLI) due to PAD and are indicated when there is disabling claudication or CLI with ischemic rest pain or ischemic tissue loss. Endovascular interventions can be safely used in the treatment of flush superficial femoral artery (SFA) occlusion in patients with critical limb ischemia with acceptable technical success, short term patency rates, and limb salvage. Failure of well conducted endovascular interventions did not preclude subsequent surgery. Adoption of trans popliteal access in cases of flush SFA occlusion is associated with high rate of technical success and can be 
done under fluoroscopic or ultrasound guidance (Bishu and Armstrong, 2015).

Endovascular intervention for chronic occlusions of the SFA are primarily performed via contralateral common femoral retrograde ("cross-over") access or ipsilateral common femoral artery antegrade access (Fanelli et al., 2011). In flush occlusion of the ostium of the SFA without a discernable stump of the vessel origin, retrograde access from the popliteal artery may be attempted with the patient in the prone or supine position (Kawarada and Yokoi, 2010). Revascularization can be performed with the patient in the supine position, with retrograde access obtained in the proximal or distal SFA (Schmidt et al., 2012).

In this study, we tried to assess the endovascular management of flush SFA total occlusion in patients with PAD and with critical chronic lower limb ischemia due to flush occlusion of the SFA with heavily calcified, long, and fibrotic lesions, of length up to $15 \mathrm{~cm}$ long.

\section{SUBJECTS AND METHODS}

Our study was a cross-sectional study, which was conducted at the Department of Vascular Surgery, inpatients and outpatients' clinics at Al-Azhar University Hospitals, Cairo, Egypt. The work started since January 2016 until January 2017.

The present work was conducted including twenty patients with chronic PAD (Rutherford-Becker categories 2- 5), their ages range was 40-65 years, with superficial femoral artery flush total occlusion including heavily calcified, long, and fibrotic lesions, and the occlusions were up to $15 \mathrm{~cm}$ long in the SFA. Our patients were selected from the patients who underwent endovascular management of flush SFA total occlusion in patients with PAD due to SFA total occlusion.

All patients were subjected to complete history, including the demographic features (age and gender), and all clinical variables (site of lesions, disease severity, disease duration, and family history of PAD). The disease duration was calculated from disease onset to time of the first visit and sociodemographic variables included the current age, disease duration and smoking habits. Also, a full accurate clinical examination, and informed consent were obtained from all the patients recruited into the study. The approval of the study was obtained from Al-Azhar Faculty of Medicine (Research Ethics Committee (REC) and Institutional Research Board (IRB) MS/17.08.69).

The decision of the endovascular management of flush SFA total occlusion was based on several factors, which included lesion length and morphology, patient body habitus, previous surgical history, and available endovascular tools.

The most commonly used was a contralateral retrograde common femoral artery (CFA) puncture to address an SFA lesion, because this approach allowed proper evaluation and treatment of concomitant iliac disease as well as allowed for a greater freedom to use devices that may require larger French sizes. The contralateral approach was the approach of choice for a flush occlusion of the SFA from its origin from the common femoral artery. However, a contralateral approach may not be successful due to the acuity of the native aortic bifurcation or in patients with prior 
aortobifemoral bypass. Additionally, it may be more difficult to generate sufficient torque and forward force on distal lesions from a contralateral approach.

The ipsilateral antegrade approach was utilized to treat patients with a nondiseased CFA, patent proximal SFA, favorable body habitus, and preserved iliac inflow. The antegrade approach on select patients with proper technique was safe and provided a more direct access to the SFA.

Another approach involved the use of an ipsilateral horizontal puncture to place a catheter in the ipsilateral iliac vessel to assess the aortoiliac segment and then reversing the puncture antegrade with a reverse curve catheter and sheath to treat the infrainguinal vessels. This technique was avoided with proper preprocedural imaging evaluations.

There were rare situations when retrograde access to the SFA was obtained from a popliteal or even dorsalis pedis approach. The use of ultrasound guidance along with a microaccess needle has been helpful in obtaining a single wall arterial puncture and reducing complications.

When there is disease of the popliteal artery, access via a dorsalis pedis artery cut-down at the dorsum of the foot were utilized. Unfortunately, patients with CLI usually have associated tibial disease, and subsequent diminished healing of the surgical access that place the foot at risk. This situation occurred rarely but may be necessary in unique situations.

Follow-up patency was assessed on a symptomatic basis only at 3, and 6 months. If symptoms persisted or returned, patients were imaged with CT angiography. Long-term outcomes were measured using length of time to the end of primary patency.

\section{Statistical Analysis:}

Statistical analysis was performed using SPSS software version 23 for Windows (SPSS Inc., Chicago, IL, USA). Continuous normally distributed data were notified using mean, and standard deviation (SD), and were compared using independent student sample t-test. Continuous non-normally distributed data were illustrated using median and range and were compared using Mann-Whitney $\mathrm{U}$ test. Categorical variables were reported using number and percentage and its related groups were compared using Pearson's chi-square test. The overall statistically significant difference was established when the two-sided $p$ value of $<0.05$. 


\section{RESULTS}

The demographic data of our study group that included 20 patients with PAD and with critical chronic lower limb ischemia due to flush occlusion of the SFA with heavily calcified, long, and fibrotic lesions, of length up to $15 \mathrm{~cm}$ long. The mean age of all patients was $59.5 \pm 6.77$ years. Regarding gender of the patients, most patients were females $(55.00 \%)$; while the remaining $(45.00 \%)$ were males. Table.1

Table (1): Socio-demographic data among 20 patients

\begin{tabular}{|l|l|c|c|c|}
\hline \multicolumn{2}{|c|}{ Parameters } & Median (Range) & Mean \pm SD & Frequency $(\%)$ \\
\hline \multicolumn{2}{|l|}{ Variables } & & & \\
\hline $\begin{array}{l}\text { Age (years) } \\
\mathrm{r}\end{array}$ & Male & & & \\
\cline { 2 - 5 } & Female & & & $9(45 \%)$ \\
\hline
\end{tabular}

As for comorbidities, all patients were diabetic, $65 \%$ with HTN, $65 \%$ were smoker, $65 \%$ were $\mathrm{CHD}$ and only $5 \%$ were CVD and $55 \%$ were with hyperlipidemia. The majority of patients were clinically presented by toe gangrene (35\%) followed by Foot gangrene (25\%) as the main presentation. Table 2

Table (2): Clinical presentation among studied group

\begin{tabular}{|l|l|l|l|}
\hline \multicolumn{2}{|l|}{ Clinical Variable } & N & $\%$ \\
\hline \multirow{4}{*}{} & Foot gangrene & 5 & 25.0 \\
\cline { 2 - 4 } & Heel infective gangrene & 2 & 10.0 \\
\cline { 2 - 4 } & Rest pain & 2 & 10.0 \\
\cline { 2 - 4 } & Sole infective gangrene & 2 & 10.0 \\
\cline { 2 - 4 } & Toe gangrene & 7 & 35.0 \\
\cline { 2 - 4 } & Toe infective gangrene & 2 & 10.0 \\
\cline { 2 - 4 } & Total & 20 & 100.0 \\
\hline
\end{tabular}

There was no significant association as regards the age or gender or the association between any of the chronic diseases or association of stent use with the savage outcome in the study group. As regards the salvage distribution among the studied group, $80.0 \%$ had favorable outcome. (Table 3) 


\section{ASSESSMENT OF THE ENDOVASCULAR MANAGEMENT OF FLUSH...}

\section{Table (3): Sex and risk factors distribution}

\begin{tabular}{|c|c|c|c|c|c|c|}
\hline \multirow{2}{*}{\multicolumn{3}{|c|}{$\begin{array}{l}\text { Salvage } \\
\text { Parameters }\end{array}$}} & & & \multirow{2}{*}{ Total } & \multirow{2}{*}{$\mathrm{P}$} \\
\hline & & & No & Yes & & \\
\hline \multicolumn{3}{|l|}{ Age } & $59.75 \pm 0.5$ & $59.37 \pm 7.43$ & & \\
\hline \multirow{2}{*}{\multicolumn{2}{|c|}{ Stent }} & Yes & $\begin{array}{c}10 \\
(62.5 \%)\end{array}$ & $4(100.0 \%)$ & & \\
\hline & & No & $6(37.5 \%)$ & $0(0 \%)$ & & \\
\hline \multirow{4}{*}{ Gender } & \multirow{2}{*}{ Female } & $\mathrm{N}$ & 2 & 9 & 11 & \multirow{4}{*}{0.82} \\
\hline & & $\%$ & $50.0 \%$ & $56.2 \%$ & $55.0 \%$ & \\
\hline & \multirow{2}{*}{ Male } & $\mathrm{N}$ & 2 & 7 & 9 & \\
\hline & & $\%$ & $50.0 \%$ & $43.8 \%$ & $45.0 \%$ & \\
\hline \multirow{4}{*}{ HTN } & \multirow{2}{*}{ No } & $\mathrm{N}$ & 2 & 5 & 7 & \multirow{4}{*}{0.48} \\
\hline & & $\%$ & $50.0 \%$ & $31.2 \%$ & $35.0 \%$ & \\
\hline & \multirow{2}{*}{ Yes } & $\mathrm{N}$ & 2 & 11 & 13 & \\
\hline & & $\%$ & $50.0 \%$ & $68.8 \%$ & $65.0 \%$ & \\
\hline \multirow{4}{*}{ Smoking } & \multirow{2}{*}{ No } & $\mathrm{N}$ & 2 & 5 & 7 & \multirow{4}{*}{0.48} \\
\hline & & $\%$ & $50.0 \%$ & $31.2 \%$ & $35.0 \%$ & \\
\hline & \multirow{2}{*}{ Yes } & $\mathrm{N}$ & 2 & 11 & 13 & \\
\hline & & $\%$ & $50.0 \%$ & $68.8 \%$ & $65.0 \%$ & \\
\hline \multirow{4}{*}{ CHD } & \multirow{2}{*}{ No } & $\mathrm{N}$ & 0 & 7 & 7 & \multirow{4}{*}{$\begin{array}{c}0.10 \\
1\end{array}$} \\
\hline & & $\%$ & $0.0 \%$ & $43.8 \%$ & $35.0 \%$ & \\
\hline & \multirow{2}{*}{ Yes } & $\mathrm{N}$ & 4 & 9 & 13 & \\
\hline & & $\%$ & $100.0 \%$ & $56.2 \%$ & $65.0 \%$ & \\
\hline \multirow{4}{*}{ CVS } & \multirow{2}{*}{ No } & $\mathrm{N}$ & 4 & 15 & 19 & \multirow{4}{*}{$\begin{array}{c}0.60 \\
8\end{array}$} \\
\hline & & $\%$ & $100.0 \%$ & $93.8 \%$ & $95.0 \%$ & \\
\hline & \multirow{2}{*}{ Yes } & $\mathrm{N}$ & 0 & 1 & 1 & \\
\hline & & $\%$ & $0.0 \%$ & $6.2 \%$ & $5.0 \%$ & \\
\hline \multirow{4}{*}{$\begin{array}{l}\text { Hyperli- } \\
\text { pidemia }\end{array}$} & \multirow{2}{*}{ No } & $\mathrm{N}$ & 2 & 7 & 9 & \multirow{4}{*}{0.82} \\
\hline & & $\%$ & $50.0 \%$ & $43.8 \%$ & $45.0 \%$ & \\
\hline & \multirow{2}{*}{ Yes } & $\mathrm{N}$ & 2 & 9 & 11 & \\
\hline & & $\%$ & $50.0 \%$ & $56.2 \%$ & $55.0 \%$ & \\
\hline \multirow{2}{*}{\multicolumn{2}{|c|}{ Total }} & $\mathrm{N}$ & 4 & 16 & 20 & \\
\hline & & $\%$ & $100.0 \%$ & $100.0 \%$ & $100.0 \%$ & \\
\hline
\end{tabular}

\section{DISCUSSION}

Endovascular treatment of SFA is challenging and restenosis is the most common cause for the lack of durability of a SFA peripheral vascular interventional procedure (Nakazato et al., 2012). Restenosis rates of SFA bare metal (nitinol) stents or BMS at 1 year exceeds $50 \%$ for lesions $\geq 60 \mathrm{~mm}$ in length or CTO. Stent based treatment of the SFA may not offer any additional advantage for short non-CTO $(<60 \mathrm{~mm})$ lesions compared to PTA (Jawaid et al., 2018). In a study, primarily comparing drug-eluting stents (DES) to balloon angioplasty in the
SFA, 12-month patency rates were $83.1 \%$ and $32.8 \%$, respectively for DES and balloon angioplasty arms (Banerjee et al., 2012).

Therefore, we carried this study as a cross sectional study with the purpose of assessing the endovascular management of flush SFA total occlusion in patients with PAD and with critical chronic lower limb ischemia due to flush occlusion of the SFA. There was no significant association as regards the age or gender or any of the chronic diseases with the savage outcome in the study group. This came in line with the analysis of the 
gender, risk factors, and Rutherford staging and its effect on the 1-year primary patency rate following endovascular management in a similar study by Hasaballah et al. (2016) to evaluate the outcomes of an endovascular intervention for femoropopliteal disease, where, their results did not find any statistically significance. However, Baril et al. (2010) reported that smokers were at a higher risk for restenosis and occlusion.

In our cohort, $35 \%$ of our patients were clinically presented with toe gangrene followed by $25 \%$ with foot gangrene as the main presentation. This was supported by Clair et al. (2012) who stated that CLI is marked by the development of rest pain, ulceration, or gangrene and is associated with high morbidity and mortality rates.

Our patients were complaining of SFA flush total occlusion including heavily calcified, long, and fibrotic lesions, range $10-340 \mathrm{~mm}$ in length in patients with PAD with critical chronic lower limb ischemia due to atherosclerotic Superficial femoral occlusive diseases. This was supported in previous clinical trials which postulated that lesions less than $5 \mathrm{~cm}$ should be initially treated with angioplasty, especially minimally calcified non-occlusive disease (Hardman et al., 2014). Therefore, we used angioplasties in our study when there was a clinical indication including symptomatic peripheral arterial disease with severe claudication, ischemic rest pain, ischemic ulceration, or ischemic tissue loss/gangrene (Rutherford stages 3$6)$.

As regards the salvage distribution among the studied group, $80.0 \%$ had favorable outcome, where we assessed the follow-up patency on a symptomatic basis only. Our savage rate comes in line with recovery rate reported in most studies and literature for the endovascular treatment in SFA occlusions. The incidence of high recanalization rates in total occlusions of more than $85 \%$ (Bradbury et al., 2010). Studies have shown that the primary 1year Limb Salvage Revascularization (LSR) ranged from 75 to $94 \%$ (Feiring et al., 2010 and Bae et al., 2013).

The endovascular treatment of SFA is associated with good success rates, being a useful and effective strategy in patients with SFA occlusive lesions less than $5 \mathrm{~cm}$. However, stenting is equivalent in those patients and are more suitable for occlusive lesions greater than $5 \mathrm{~cm}$ (Marcucci et al., 2015).

Future work to investigate in multicenters is needed to elucidate the clinical implications relevant to our findings over longer follow-up periods. Also, future studies will continue to provide both clinicians and researchers with new insights into our understanding of the role of the endovascular management of the flush SFA total occlusion in patients with PAD due to SFA total occlusion in patients with CLI and the role of stenting.

\section{CONCLUSION}

Endovascular management strategies of flush SFA total occlusion in patients with PAD due to SFA total occlusion were safely used in the treatment of flush superficial femoral artery occlusion in patients with critical limb ischemia with acceptable technical success, short term patency rates, and limb salvage. 


\section{REFERENCES}

1. Bae, J.-I., Won, J. H., Han, S. H., Lim, S. H., Hong, Y. S., Kim, J. Y. and Kim, J.-S. (2013): Endovascular revascularization for patients with critical limb ischemia: impact on wound healing and long term clinical results in 189 limbs. Korean Journal of Radiology, 14(3): 430-438.

2. Banerjee, S., Das, T. S., Abu-Fadel, M. S., Dippel, E. J., Shammas, N. W., Tran, D. L. and Weideman, R. A. (2012): Pilot trial of cryoplasty or conventional balloon post-dilation of nitinol stents for revascularization of peripheral arterial segments: the COBRA trial. Journal of the American College of Cardiology, 60(15): 1352-1359.

3. Baril, D. T., Chaer, R. A., Rhee, R. Y., Makaroun, M. S. and Marone, L. K. (2010): Endovascular interventions for TASC II D femoropopliteal lesions. Journal of Vascular Surgery, 51(6): 14061412 .

4. Bishu, K., and Armstrong, E. J. (2015): Endovascular revascularization of a surgically ligated superficial femoral artery: A case report. Catheterization and Cardiovascular Interventions, 86(7): 1236-1241.

5. Bradbury, A. W., Adam, D. J., Bell, J., Forbes, J. F., Fowkes, F. G. R. and Gillespie (2010): Bypass versus Angioplasty in Severe Ischaemia of the Leg (BASIL) trial: an intention-to-treat analysis of amputation-free and overall survival in patients randomized to a bypass surgery-first or a balloon angioplasty-first revascularization strategy. Journal of Vascular Surgery, 51(5): 5S-17S.

6. Clair, D., Shah, S., and Weber, J. (2012): Current state of diagnosis and management of critical limb ischemia.
Current Cardiology Reports, 14(2): 160170.

7. Fanelli, F., Lucatelli, P., Allegritti, M., Corona, M., Rossi, P., and Passariello, R. (2011): Retrograde popliteal access in the supine patient for recanalization of the superficial femoral artery: initial results. Journal of Endovascular Therapy, 18(4):503-509.

8. Feiring, A. J., Krahn, M., Nelson, L., Wesolowski, A., Eastwood, D., and Szabo, A. (2010): Preventing leg amputations in critical limb ischemia with below-the-knee drug-eluting stents: the PaRADISE (PReventing Amputations using Drug eluting StEnts) trial. Journal of the American College of Cardiology, 55(15): 1580-1589.

9. Hardman, R. L., Jazaeri, O., Yi, J., Smith, M. and Gupta, R. (2014): Overview of classification systems in peripheral artery disease. Paper presented at the Seminars in Interventional Radiology, 31 (4): 378-388.

10. Hasaballah, A., Saleh, M. and Ali, H. (2016): Endovascular interventions for long occlusive disease of the superficial femoral artery in critical limb ischemia. The Egyptian Journal of Surgery, 35(4): 414-417.

11. Jawaid, O., Jeon-Slaughter, H., Kokkinidis, D., Banerjee, S. and Armstrong, E. J. (2018): Use of drugeluting stents versus standard nitinol stents after drug-coated balloon angioplasty of the superficial femoral artery: insights from the multicenter excellence in peripheral artery disease (XLPAD) registry. Journal of the American College of Cardiology, 71(11 Supplement): A1099-1102.

12. Kawarada, O. and Yokoi, Y. (2010): Retrograde 3-French popliteal approach in the supine position after failed antegrade angioplasty for chronic superficial 
femoral artery occlusion. Journal of Endovascular Therapy, 17(2): 255-258.

13. Marcucci, G., Accrocca, F., Gabrielli, R., Antonelli, R., Giordano, A., De, G. V., and Siani, A. (2015): Combining superficial femoral artery endovascular treatment with distal vein bypass. The Journal of Cardiovascular Surgery, 56(3): 383-391.

14. Nakazato, J., Hiramori, S., Tomoi, Y., Tosaka, A., Soga, Y., Yokoi, H. and Nobuyoshi, M. (2012): Balloon Angioplasty versus Implantation of
Nitinol Stents in Small Diameter Vessel and Intermediate Length Superficial Femoral Artery Lesions: Am Heart Assoc. Circulation, 126 (21): A1466-1470.

15. Schmidt, A., Bausback, Y., Piorkowski, M., Werner, M., Bräunlich, S., Ulrich, M. and Botsios, S. (2012): Retrograde recanalization technique for use after failed antegrade angioplasty in chronic femoral artery occlusions. Journal of Endovascular Therapy, 19(1): 23-29. 


\section{تقييم التذخل الجوف و عائى لمناجزة الإنسداد الكلى للثريان الفخذى السطحى من منبعه}

محمد عبدالحميل عبد الرحمن، محمد يحيى زكريا، كريم محمدي عيد محمدي

قسم جراحة الأوعية الاموية، كلية الطب، جامعة الأزهر

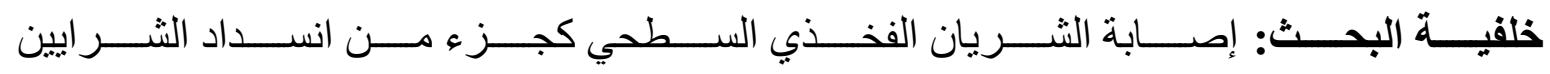

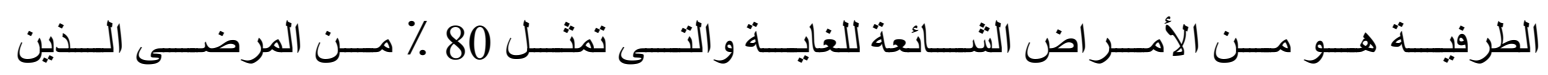

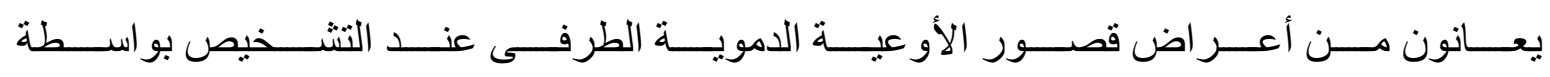
تصوير الأوعية الدموية.

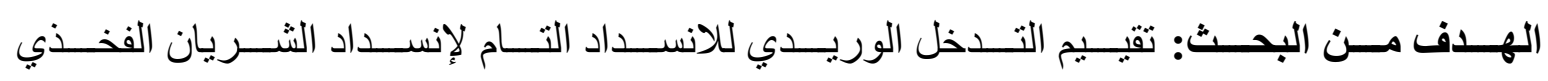

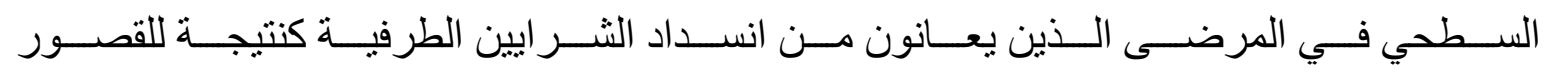

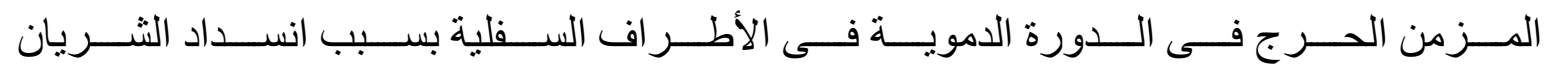
الفذذي السطحي في قسم جر احة الأوعية الدموية في مستشفيات جامعة الأزهر.

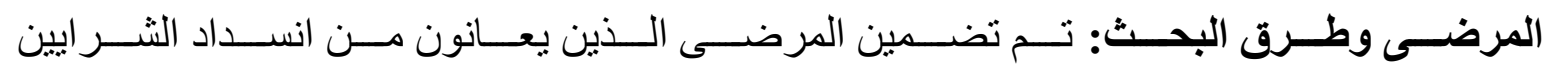

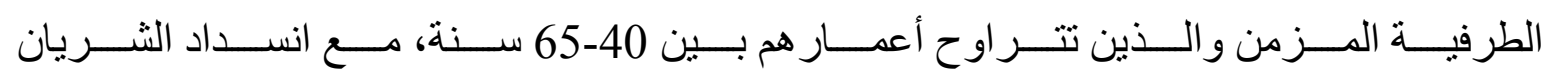

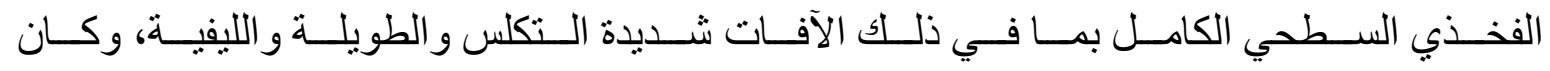

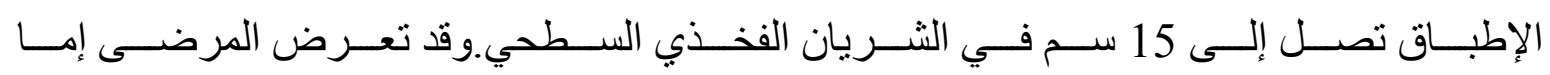

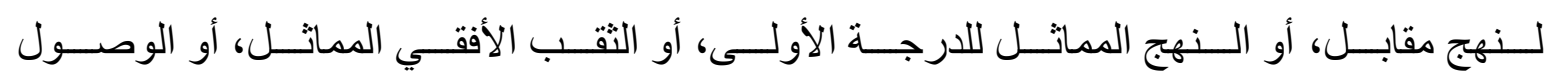
الرجعي إلى الثريان الفخذي السطحي عن طريق المأزق المأبضي أو الظهري.

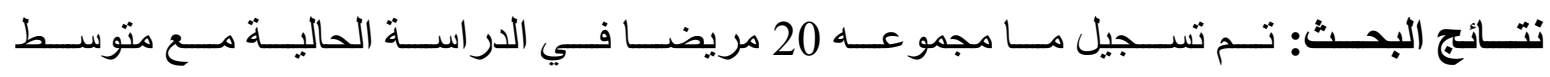

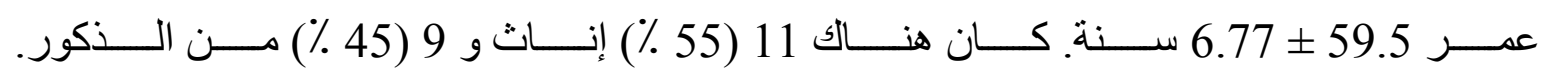

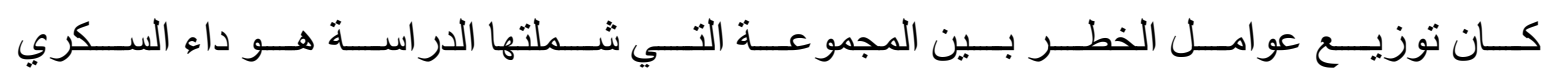

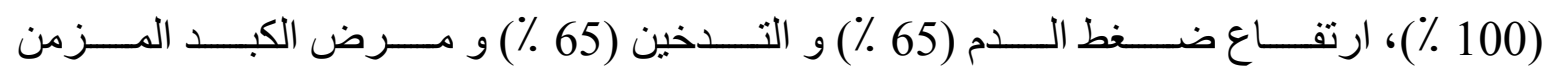

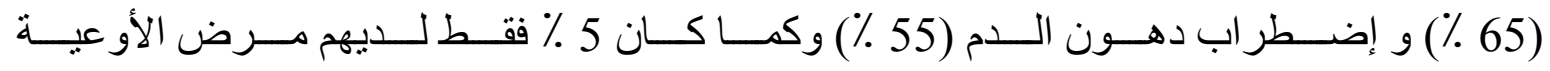

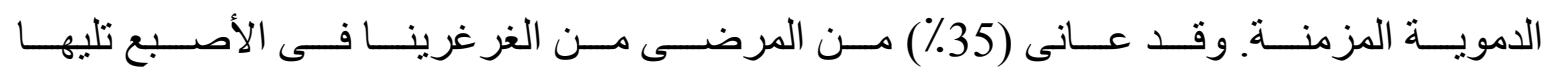
الغرغرين القدمي (25\%) كعرض مرضى رئيسي. 


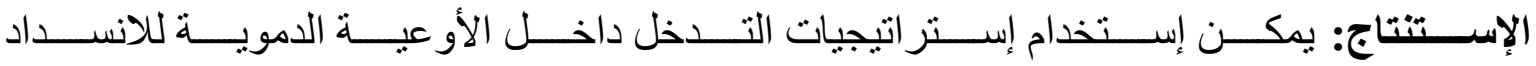

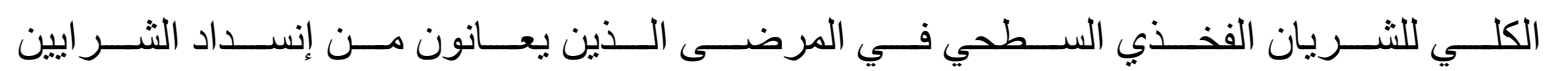

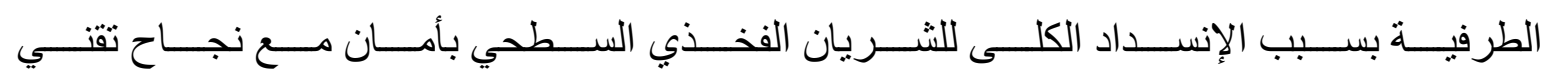
مقبول، ومعدلات نجاح مقبولة للأو عية المسدودة، وإنقاذ الأطر اف المصابة. 